\title{
The Effect of a Cardiovascular Self-Management Support Program on Preventing Cardiovascular Complication Behaviors and Clinical Outcomes in the Elderly with Poorly Controlled Type 2 Diabetes Mellitus in Indonesia
}

\author{
Dayan HISNI ${ }^{1,2, *}$, Tippamas CHINNAWONG ${ }^{3}$ and \\ Ploenpit THANIWATTANANON ${ }^{3}$ \\ ${ }^{I}$ Department of Medical and Surgical Nursing, Faculty of Health Sciences, University of Nasional, \\ Jakarta, Indonesia \\ ${ }^{2}$ Faculty of Nursing, Prince of Songkla University, Songkhla 90110, Thailand \\ ${ }^{3}$ Department of Medical Nursing, Faculty of Nursing, Prince of Songkla University, \\ Songkhla 90110, Thailand
}

('Corresponding author's e-mail: dayanhisni@gmail.com)

Received: 26 August 2016, Revised: 17 January 2017, Accepted: 6 February 2017

\begin{abstract}
Elderly people with poorly controlled type 2 DM often develop cardiovascular disease (CVD) as a major complication. Prevention can be managed by the action of preventing cardiovascular complication behaviors (PCCB) which consist of a DM and healthy heart diet, physical exercise, taking medication regularly, and ceasing smoking. The cardiovascular self-management support program (CSSP) facilitates successful and improved PCCB and clinical outcomes in the elderly with poorly controlled type 2 DM. A quasi-experimental study was conducted to find out the effectiveness of CSSP on PCCB and clinical outcomes in elderly with poorly controlled type 2 DM. Fifty-nine elders with poorly controlled type 2 DM were randomly recruited and divided into an experimental and a control group. Of these, 30 participants in the experimental group received the CSSP and the usual care whereas the control group only received the usual care. PCCB was measured by the prevention of cardiovascular complication behaviors questionnaire (PCCBQ), while clinical outcomes were measured by clinical devices provided by the Public Health Center. An independent $t$-test was conducted to determine the effect of the program between groups and a paired $t$-test was used to report the effect of the program within the group. The results showed that the mean score of the PCCB in the experimental group was significantly higher than those in the control group after participating in the program $(p<.05)$ and improved the mean scores of the clinical outcomes except for the diastolic blood pressure $(p>.05)$. The CSSP in this study clearly indicates positive effects on improving the PCCB and some clinical outcomes in the elderly with poorly controlled type $2 \mathrm{DM}$.
\end{abstract}

Keywords: Cardiovascular disease (CVD), self-management support program, behaviors to prevent cardiovascular complications, poorly controlled type $2 \mathrm{DM}$, elderly patients

\section{Introduction}

Type 2 Diabetes Mellitus (DM) in the elderly is a global health problem as much as some developing countries and Indonesia is among these [1]. The high prevalence of type 2 DM in the elderly is associated with poor glycemic control [2]. The characteristic of elderly people with poorly controlled type $2 \mathrm{DM}$ is an HbA1c level $>7 \%$ or fasting blood glucose (FBG) $\geq 154 \mathrm{mg} / \mathrm{dl}[2,3]$. Endothelial dysfunction, oxidative stress, and inflammation in this population play a central role in developing cardiovascular disease (CVD) complications [4,5]. Controlling risk factors of CVD complications is necessary to reduce its prevalence [6].

The goal of treatment for preventing CVD complications in the elderly with DM must be individualized and should focus on the potential for greater harm [7] due to their greater physical limitations, a decline in cognitive function, and physiological changes that affect self-management ability to prevent CVD complications [8]. Preventing CVD complications in the elderly with DM can be carried 
http://wjst.wu.ac.th

out by implementing preventing cardiovascular complication behaviors which consist of a DM and healthy heart diet, physical exercise, taking medication regularly, and ceasing smoking [3]. Furthermore, reducing clinical factors such as FBG, lipid profiles, and blood pressure (BP) as CVD risk factors should be done as these clinical factors are linked to enlarged and ruptured artery walls as well as rapid development of myocardial infarction [9].

Elderly people with DM have special needs so as to improve behavior and clinical factors to prevent CVD complications. They are associated with various troubles regarding their abilities to perform selfmanagement because of functional changes caused by aging, physiological and social problems [10]. These changes impact managing DM complications through the doctor's instruction or drugs alone [11]. Also, they need social support such as support from family members to achieve behavioral change goals [12]. Therefore, elderly people with poorly controlled type 2 DM need diabetes self-management support to improve the self-management behaviors and be physically active [13].

The effectiveness of self-management has been proven as a basic foundation for empowering health behaviors, and has improved clinical outcomes in patients with DM. Performing 5 A's self-management support could facilitate self-management behaviors and change behaviors in patients with chronic illnesses such as diabetes [14]. The 5 A's self-management support is a counseling approach that entails a series of sequential steps to facilitate self-management and behavioral change. The process of 5 A's selfmanagement support consists of assess, advise, agree, assist, and arrange [15].

Previous studies have been conducted regarding self-management support. The 5 A's selfmanagement support has been proven to improve health behaviors, FBG, lipid profiles, and BP in patient with metabolic syndrome in Thailand [16]. Self-management support could improve health behaviors in patients with poorly controlled type 2 DM [13]. In Indonesia, self-management support could also improve the behaviors to prevent diabetic foot ulcers [17], improve dietary and exercise behaviors, and clinical outcomes in the general DM population [18].

At the present time, there have been no studies that use a 5 A's self-management support program to improve the PCCB and clinical outcomes which were FBG, total-cholesterol, HDL-cholesterol, LDLcholesterol, and BP in elderly people with poorly controlled type $2 \mathrm{DM}$ especially in Indonesia to prevent CVD complications. It is necessary as Indonesia is a country with a high prevalence of DM in elderly people who are aged more than 60 years [1] and the prevalence of CVD complications in those population is also high [19]. Therefore, the cardiovascular self-management support program is important and by applying a 5 A's self-management support we hoped to improve the PCCB and clinical outcomes in the elderly with poorly controlled type $2 \mathrm{DM}$ in Indonesia.

\section{Materials and methods}

The quasi-experimental study, 2 groups, pre-test and post-test design was conducted between January 2016 to April 2016 at the Elderly Health Care Unit, Public Health Center, Cilegon City, Indonesia. The sample size was calculated based on the power analysis technique with a significance level of 0.05 , power of 0.80 , and the effect size (d) of 1.83 as obtained from a previous study [18]. There were 59 participants who completed the study in which 30 participants were in the experimental group (EG) and 29 participants in the control group (CG).

Samples were recruited based on the inclusion criteria, then randomly assigned to either the EG or CG using a matching technique based on age and gender. The EG received the cardiovascular selfmanagement support program and usual care while the CG only received the usual care based on the guidelines from Elderly Health Care Unit, Public Health Center, Cilegon City, Indonesia.

The inclusion criteria were aged $\geq 60$ years old, FBG $\geq 154 \mathrm{mg} / \mathrm{dl}$ in the past 3 months or HbA1c level $>7 \%$, duration of diabetes at least 1 year, able to communicate in Indonesian, both verbally and written, can be contacted by telephone and home visit, have no hearing impairment, have a family member who stays with the elderly person, and no mental health problems. Participants signed informed consents before they participated in this study and participation was terminated if participants developed a severe condition during the program or could not join all sessions of the interventions.

The researchers provided a booklet regarding preventing cardiovascular complication behaviors which contained information regarding the DM and healthy heart diets, exercise for the elderly with poorly controlled type $2 \mathrm{DM}$, medications to prevent CVD complications, and ceasing smoking. This booklet was made by the researchers. Every participant followed this booklet as a guideline to perform the preventing cardiovascular complication behaviors. 


\section{Data collection}

The instruments used were the Demographic Data Questionnaire and Health Related Information (DDQHRI), Preventing Cardiovascular Complication Behaviors Questionnaire (PCCBQ), and clinical outcome measurements.

The DDQHRI, developed by the researchers, consisted of age, gender, education level, family member taking care of the elderly, the last FBG, total-cholesterol, HDL-cholesterol, LDL-cholesterol, systolic blood pressure (SBP), and diastolic blood pressure (DBP).

The PCCBQ, an instrument used to measure the PCCB, was modified by the researchers based on the previous study [20] with Cronbach's alpha coefficient of 0.88 . This instrument divided into 4 subscales which were DM diet and healthy heart diet, physical exercise, taking medications regularly, and smoking cessation with total 25 questions. Each item has been measured by using a 5-point Likert scale. The higher scores of PCCBQ indicated that elderly were more frequent to perform PCCB.

Clinical outcome measurements were the FBG that was measured using GlucoDr ${ }^{\circledR}$, total-cholesterol, HDL-cholesterol, LDL-cholesterol measured using LipidPro ${ }^{\mathrm{TM}}$, and BP measured using an OMRON IA2 automatic blood pressure monitor.

\section{Procedure of the cardiovascular self-management support program}

The cardiovascular self-management support program (CSSP) was developed based on the 5 A's self-management support model proposed by Glasgow et al. [14]. The program aimed to improve the PCCB and clinical outcomes to prevent CVD complications. Participants who were in the EG received individual instruction of the CSSP and usual care for 8 weeks and involved a family member. An individual session was held in 6 education and discussion sessions face to face, and 2 sessions by telephone (60 $\mathrm{min} / \mathrm{session})$.

The process of CSSP was (1) assessing current confidence, belief, and behaviors of the participants; (2) providing specific information by an educational and counseling session regarding PCCB. In this process, family members of the participants were involved. The activities included explaining about the benefit of a DM and healthy heart diet by reducing carbohydrate intake, sugar intake, and following the DASH diet to prevent CVD complications, walking is the best physical exercise for the elderly with poorly controlled type $2 \mathrm{DM}$, the benefit of taking medications regularly to prevent CVD complications, and explaining about the negative effect of smoking that could develop CVD complications quickly. Furthermore, these behaviors could improve clinical outcomes such as FBG, lipid profiles, and BP; known risk factors of CVD complications in the elderly with diabetes. Moreover, in this process, the researchers also provided and distributed the PCCB booklet and medications log book for the participants and their family member as a guideline to perform the PCCB. The booklet contained information regarding the PCCB and the role of the family member to improve the PCCB of the participants, whereas the medications log book was used to record the activity of the participants in terms of taking medications regularly; then (3) collaborating between the researchers, the participants, and their family member to set specific goals regarding the PCCB, participants could modify, change, and manage their PCCB based on the specific goals to achieve those goals.

The next process was (4) assisting the participants and their family member to develop personal action plans to meet the goals. The activities listed were specific goals for the PCCB, identification of possible barriers related to the $\mathrm{PCCB}$, discussion of techniques to overcome these barriers during the PCCB, and the last process (5) encouraging the participants to maintain their behaviors to achieve their goals and arranging for time for follow-up planning both by telephone and face to face at the Elderly Health Care Unit and home visit. The activities in each session were continued every week for 8 weeks.

The participants who were in the CG only received the usual care based on the guidelines from the Public Health Center, including a free regular check-up once a month to monitor blood glucose, blood pressure, lipid profiles, and general health education about taking medications and DM diet held by the nurse as well as an aerobic class for the elderly once a week based on the clients' interest. However, there was no specific education to prevent CVD complications by PCCB. Data and blood samples of both groups were collected by the research assistants at the baseline and at 8 weeks after the program was implemented.

\section{Data analysis}

Descriptive statistics were used to analyze the DDQHRI. Chi-square, Fisher's exact test, and independent $t$-test were used to examine the difference in characteristics between the EG and CG at the baseline. The assumption of normality and homogeneity of variance of the variables have been conducted before to determine the appropriate statistical analysis. The researchers used the independent $t$-test for 
http://wjst.wu.ac.th

testing the differences of mean score of the PCCB and clinical outcomes between the EG and CG, while a paired $t$-test was used to test the differences of mean score of the PCCB clinical outcomes in both the EG and the CG before and after receiving the CSSP.

\section{Results and discussion}

Demographic data and health related information

There was no significant difference between the EG and the CG at the baseline of the DDQHRI in the elderly with poorly controlled type $2 \mathrm{DM}$.

Table 1 Demographic data and health related information.

\begin{tabular}{|c|c|c|c|c|c|c|}
\hline \multirow{2}{*}{ Characteristics } & \multicolumn{2}{|c|}{ Experimental group (EG) } & \multicolumn{2}{|c|}{ Control group (CG) } & \multirow{2}{*}{$\begin{array}{c}\text { Statistic } \\
\text { values }\end{array}$} & \multirow{2}{*}{$p$} \\
\hline & $\mathrm{n}_{1}$ & $\%$ & $\mathbf{n}_{2}$ & $\%$ & & \\
\hline Age & & & & & & \\
\hline$($ Min - Max $=60-77$ years $)$ & $M=62.90$ & $S D=3.75$ & $M=63.17$ & $S D=3.57$ & $.28^{\mathrm{c}}$ & 77 \\
\hline Gender & & & & & $.14^{\mathrm{a}}$ & .70 \\
\hline Male & 7 & 23.3 & 8 & 27.6 & & \\
\hline Female & 23 & 76.7 & 21 & 72.4 & & \\
\hline Family taking care of elderly & & & & & $6.57^{\mathrm{a}}$ & .11 \\
\hline Children & 24 & 80 & 15 & 51.7 & & \\
\hline Wife & 1 & 3.3 & 3 & 10.43 & & \\
\hline Husband & 5 & 16.7 & 7 & 24.1 & & \\
\hline Children and wife & 0 & 0 & 2 & 6.9 & & \\
\hline Children and husband & 0 & 0 & 2 & 6.9 & & \\
\hline The last FBG (mg/dl) & & & & & $.06^{\mathrm{c}}$ & .24 \\
\hline$(\operatorname{Min}-\operatorname{Max}=154-406)$ & $M=227.97$ & $S D=78.71$ & $M=206.38$ & $S D=62.85$ & & \\
\hline The last total-cholesterol (mg/dl) & & & & & $.20^{\mathrm{c}}$ & .62 \\
\hline$(\operatorname{Min}-\operatorname{Max}=120-233)$ & $M=183.70$ & $S D=25.12$ & $M=191.31$ & $S D=20.10$ & & \\
\hline The last HDL-cholesterol (mg/dl) & & & & & $.81^{\mathrm{c}}$ & .92 \\
\hline$(\operatorname{Min}-\operatorname{Max}=31-67)$ & $M=48.77$ & $S D=9.67$ & $M=49$ & $S D=8.79$ & & \\
\hline The last LDL-cholesterol (mg/dl) & & & & & $.57^{\mathrm{c}}$ & .68 \\
\hline$(\operatorname{Min}-\operatorname{Max}=45-120)$ & $M=78.27$ & $S D=19.02$ & $M=80.21$ & $S D=17.40$ & & \\
\hline The last SBP (mmHg) & & & & & $.45^{\mathrm{c}}$ & .62 \\
\hline$(\operatorname{Min}-\operatorname{Max}=120-176)$ & $M=149.43$ & $S D=12.52$ & $M=150.93$ & $S D=10.71$ & & \\
\hline The last DBP (mmHg) & & & & & $.40^{\mathrm{c}}$ & .19 \\
\hline$(\operatorname{Min}-\operatorname{Max}=80-105)$ & $M=87.17$ & $S D=5.82$ & $M=85.17$ & $S D=5.74$ & & \\
\hline
\end{tabular}

Effect of cardiovascular self-management support program (CSSP) on preventing cardiovascular complications behaviors (PCCB) in elderly with poorly controlled type 2 DM

Table 2 shows the mean score of the PCCB between the EG and the CG before receiving the program which showed no significant difference $(t=-1.72, p<.05)$. However, after receiving the program, the mean score of the PCCB showed a significant difference between the EG and the CG $(t=$ $24.01, p=<.05)$. 
http://wjst.wu.ac.th

Table 2 Pre-test and post-test mean scores of the PCCB.

\begin{tabular}{|c|c|c|c|c|c|c|c|c|}
\hline \multirow[t]{2}{*}{ Variable } & \multicolumn{2}{|c|}{$\begin{array}{c}\text { Experimental group (EG) } \\
n_{1}=\mathbf{3 0}\end{array}$} & \multicolumn{2}{|c|}{$\begin{array}{c}\text { Control group (CG) } \\
n_{2}=29\end{array}$} & \multicolumn{2}{|c|}{$95 \%$ CI } & \multirow[t]{2}{*}{$t$} & \multirow[t]{2}{*}{$p$} \\
\hline & $\mathbf{M}$ & SD & M & SD & Lower & Upper & & \\
\hline \multicolumn{9}{|l|}{ PCCB } \\
\hline Pre-test & 50.87 & 15.52 & 56.69 & 9.54 & -12.56 & .92 & -1.72 & .07 \\
\hline Post-test & 91.20 & 3.30 & 59.07 & 6.43 & 29.43 & 34.83 & 24.01 & .00 \\
\hline
\end{tabular}

$M=$ mean score, $S D=$ standard deviation

Table 3 shows the comparison of the PCCB mean score within the EG and CG. In the EG, there was a statistically significant difference between the pre-test and post-test mean scores on PCCB $(t=-$ $14.83, p<.05)$. In contrast, participants in the control group reported that there was no significant difference between pre-test and post-test mean score on PCCB $(t=-1.54, p>.05)$.

Table 3 Comparison of the pre-test and post-test mean score of the PCCB.

\begin{tabular}{|c|c|c|c|c|c|c|c|c|}
\hline \multirow{2}{*}{ Variable } & \multicolumn{2}{|c|}{ Pre-test } & \multicolumn{2}{|c|}{ Post-test } & \multicolumn{2}{|c|}{$95 \%$ CI } & \multirow[b]{2}{*}{$t$} & \multirow[b]{2}{*}{$p$} \\
\hline & $\mathbf{M}$ & SD & M & SD & Lower & Upper & & \\
\hline Experimental gi & & & & & & & & \\
\hline РCCB & 50.87 & 15.52 & 91.20 & 3.30 & -45.89 & -34.77 & -14.83 & .00 \\
\hline Control group & & & & & & & & \\
\hline PCCB & 56.69 & 9.54 & 59.07 & 6.43 & -5.53 & .77 & -1.54 & .13 \\
\hline
\end{tabular}

$M=$ mean score, $S D=$ standard deviation

Effect of cardiovascular self-management support program on clinical outcomes in elderly with poorly controlled type $2 \mathrm{DM}$

Table 4 shows the mean scores of the clinical outcomes. Before receiving the program, it demonstrated no significant difference between the EG and the CG $(p>.05)$, except for DBP $(p<.05)$. However, after receiving the program, the clinical outcomes showed a significant difference between the EG and the CG $(p<.05)$, except for the DBP $(p>.05)$.

Table 4 Pre-test and post-test mean scores of the clinical outcomes.

\begin{tabular}{|c|c|c|c|c|c|c|c|c|}
\hline \multirow[t]{2}{*}{ Variable } & \multicolumn{2}{|c|}{$\begin{array}{c}\text { Experimental group (EG) } \\
\mathbf{n}_{1}=\mathbf{3 0}\end{array}$} & \multicolumn{2}{|c|}{$\begin{array}{c}\text { Control group (CG) } \\
\mathrm{n}_{2}=29\end{array}$} & \multicolumn{2}{|c|}{$95 \%$ CI } & \multirow[t]{2}{*}{$t$} & \multirow[t]{2}{*}{$p$} \\
\hline & M & SD & $\mathbf{M}$ & SD & Lower & Upper & & \\
\hline \multicolumn{9}{|c|}{ Clinical outcomes (pre-test) } \\
\hline FBG & 220.17 & 70.54 & 195.10 & 69.47 & -11.45 & 61.57 & 1.37 & .17 \\
\hline Total-cholesterol & 195.30 & 35.98 & 198.96 & 28.94 & -20.46 & 13.55 & -.40 & .68 \\
\hline HDL-cholesterol & 46.73 & 8.90 & 45.52 & 7.37 & -3.04 & 5.47 & .57 & .56 \\
\hline LDL-cholesterol & 83.53 & 30.01 & 85.24 & 16.08 & -14.32 & 10.91 & -.27 & .78 \\
\hline SBP & 145.33 & 20.12 & 149.66 & 18.02 & -14.29 & 5.65 & -.86 & .38 \\
\hline DBP & 84.67 & 5.71 & 88.62 & 6.39 & -7.12 & -.78 & -2.50 & .01 \\
\hline \multicolumn{9}{|c|}{ Clinical outcomes (post-test) } \\
\hline FBG & 142.20 & 36.43 & 182.31 & 53.20 & -64.04 & -16.18 & -3.36 & .00 \\
\hline Total-cholesterol & 156.97 & 40.06 & 190.38 & 44.55 & -55.53 & -11.28 & -3.02 & .00 \\
\hline HDL-cholesterol & 54.10 & 8.36 & 42.38 & 7.13 & 7.67 & 15.77 & 5.79 & .00 \\
\hline LDL-cholesterol & 64.67 & 16.20 & 96.59 & 31.03 & -45.08 & -18.75 & -4.89 & .00 \\
\hline SBP & 134.33 & 13.30 & 144.83 & 16.30 & -18.26 & -2.72 & -2.70 & .00 \\
\hline DBP & 82.33 & 4.30 & 83.79 & 6.21 & -4.26 & 1.34 & -1.04 & .30 \\
\hline
\end{tabular}


http://wjst.wu.ac.th

Table 5 shows the comparison of the clinical outcomes mean scores within the EG and CG. Participants in the EG showed significant differences in FBG, total-cholesterol, HDL-cholesterol, LDLcholesterol, and SBP before and after receiving the program $(p<.05)$ except for DB $(p>.05)$. In contrast to the participants in the $\mathrm{CG}$, there were no significant differences in the clinical outcomes before and after receiving the program $(p>.05)$, except for the DBP $(p<.05)$.

Table 5 Comparison of the pre-test and post-test mean scores of the clinical outcomes within the EG and CG.

\begin{tabular}{|c|c|c|c|c|c|c|c|c|}
\hline \multirow{2}{*}{ Variables } & \multicolumn{2}{|c|}{ Pre-test } & \multicolumn{2}{|c|}{ Post-test } & \multicolumn{2}{|c|}{$95 \%$ CI } & \multirow{2}{*}{$T$} & \multirow{2}{*}{$p$} \\
\hline & M & SD & M & SD & Lower & Upper & & \\
\hline \multicolumn{9}{|c|}{ Clinical outcomes in EG } \\
\hline FBG & 220.17 & 70.54 & 142.20 & 36.43 & 57.50 & 98.43 & 7.79 & .00 \\
\hline Total-cholesterol & 195.30 & 35.98 & 156.97 & 40.06 & 24.27 & 52.39 & 5.57 & .00 \\
\hline HDL-cholesterol & 46.73 & 8.90 & 54.10 & 8.36 & -11.83 & -2.89 & -3.37 & .00 \\
\hline LDL-cholesterol & 83.53 & 30.01 & 64.67 & 16.20 & 8.46 & 29.27 & 3.70 & .00 \\
\hline SBP & 154.33 & 20.12 & 134.33 & 13.30 & 4.84 & 17.15 & 3.65 & .00 \\
\hline DBP & 84.67 & 5.71 & 82.33 & 4.30 & -.20 & 4.86 & 1.88 & .07 \\
\hline \multicolumn{9}{|c|}{ Clinical Outcomes in CG } \\
\hline FBG & 195.10 & 69.47 & 182.31 & 53.20 & -6.94 & 32.52 & 1.32 & .19 \\
\hline Total-cholesterol & 198.76 & 28.94 & 190.38 & 44.55 & -12.42 & 29.18 & .82 & .41 \\
\hline HDL-cholesterol & 45.52 & 7.37 & 42.38 & 7.13 & -1.25 & 7.53 & 1.46 & .15 \\
\hline LDL-cholesterol & 85.24 & 16.08 & 96.59 & 31.03 & -23.25 & .56 & -1.95 & .06 \\
\hline SBP & 149.66 & 18.02 & 144.83 & 16.30 & -2.54 & 12.20 & 1.34 & .19 \\
\hline DBP & 88.62 & 6.39 & 83.79 & 6.21 & 1.21 & 8.43 & 2.73 & .01 \\
\hline
\end{tabular}

$M=$ mean score, $S D=$ standard deviation

\section{Discussion}

This study found that the average age of the participants was 62 years in the EG and 63 years in the CG. The prevalence of type $2 \mathrm{DM}$ in the elderly was more than twice that of middle-aged adults and peaks at $60-74$ years old [21]. The elderly with poorly controlled type 2 DM in this study lived with their children. The children accompanied and assisted the elderly to perform the PCCB. Similar to previous studies the family member had a positive impact on improving diabetes self-management behaviors and health outcomes including FBG and HbA1c $[12,22]$. Furthermore, elderly people with poorly controlled type $2 \mathrm{DM}$ both in the EG and CG had normal levels of CVD risk factors which were the last totalcholesterol, HDL-cholesterol, LDL-cholesterol, SBP, and BP except for the last FBG which was high in both groups.

The improvement of PCCB in this study was due to the application of the 5 A's self-management support model. This model consisted of assess, advice, agree, assist, and arrange [14,15]. The researchers assessed the knowledge, skill, and belief of the elderly with poorly controlled type 2 DM in the beginning. The result of this process was to gain a deep understanding about the self-management issue and belief of the participants. The advice process in this study involved the researchers providing specific individual information regarding PCCB which concerned the DM and healthy heart diet, physical exercise, taking medications regularly, and ceasing smoking to the participants by involving their family member. It was consistent with a previous study that revealed that giving education individually enabled the patient to feel free to either gain more knowledge or share their experience based on achieving goals and problem solving when they faced barriers [23]. However, it is in contrast with a previous study that reported that information provided in a group was better in achieving goals in the elderly with diabetes because they could ask others in the group about any unclear information [24].

Improving PCCB in the elderly with poorly controlled type $2 \mathrm{DM}$ was also probably due to the contribution of the PCCB booklet. This booklet was useful for the participants and their family member in regards to their daily lives as well as improving their knowledge. It has been found that written guidelines effectively improve knowledge and behaviors in patients with diabetes [25]. Furthermore, during the study, the researchers continued the agreed process by collaborating with the participants and their family member to set specific goals of the PCCB and the clinical outcomes levels achievement every week so that they could perform the PCCB well in their daily lives to reach these goals. It was consistent with 
previous studies which have reported that incorporating collaborative goals into routine primary care practice is a useful strategy to promote behavior change [23]. Also, the purpose of setting goals was to initiate behavioral changes and improve clinical outcomes [26].

Developing the personal action plans also contributed in improving PCCB in the elderly with poorly controlled type $2 \mathrm{DM}$ by identifying the possible barriers, discussion, using problem solving to address the barriers, and sharing action plans with the researchers. During the study, some of the elderly with poorly controlled type $2 \mathrm{DM}$ found the barriers relating to the culture of the DM and healthy heart diet in Indonesia. For instance, the celebration of the Prophet Muhammad's birthday called Maulid, praying for dead people during the first to seventh day called Tahlilan. During these celebrations, each family prepares a lot of food in which they do not consider about the amount of carbohydrate, sugar, and fat. Also, during these celebrations, the families invite their neighbors to celebrate, pray, and eat together. Consequently, some elderly with poorly controlled type 2 DM had difficulty in managing the challenges to perform PCCB especially for the DM and healthy heart diet during celebrations. The strategy to solve these barriers came from the family member of elderly person. He/she was important to remind them to avoid certain foods during the celebration.

In this study, family support led to improved PCCB in the elderly with poorly controlled type 2 DM. Family support is a part of assist process of the $5 \mathrm{~A}$ 's self-management support model. Similar to another study reported that elderly with DM need family support to achieve the goals of behavioral change $[14,26]$. The role of the family member who supported the elderly with poorly controlled type 2 DM was reminding them to eat food based on the DM and healthy heart diet to prevent CVD complications, preparing foods for the elderly, performing and accompanying elderly to do physical exercise as recommended by the researcher, reminding them to take their medications as scheduled, and record the activities of the elderly in term of taking medications into the medications log-book every day. Similar to a previous study that revealed that to achieve the behavioral change goals a family member, health care professional, or other care givers should be involved [27].

The last reason in terms of improving PCCB in the elderly with poorly controlled type 2 DM was that they received weekly follow-ups both by telephone and face to face. This method could improve the confidence of the elderly and expectations to change and maintain positive behaviors. This finding was consistent with a previous study which reported that intervention using phone calls and face to face follow-ups were effective in improving self-management behaviors such as dietary and physical exercise $[28,29]$. Furthermore, the self-management program should include longer-term follow-up processes to ensure that positive behavioral changes occurred.

Moreover, according to Table 5, some clinical outcomes in the EG were improved which were FBG, total-cholesterol, HDL-cholesterol, LDL-cholesterol, and SBP after receiving a cardiovascular selfmanagement support program. These improvements were due to participants in the EG performing well in term of PCCB. First, they performed the DM and healthy heart diet by the Dietary Approach to Stop Hypertension (DASH) diet which consisted of protein, reduce total fat intake, whole grains, low fat dairy products, rich in fruits and vegetables, and limit sodium intake to no more than one teaspoon per day. Similar to a previous study the DASH diet significantly reduced the FBG level, HbA1c, lipid profiles, and body weight [30]. The mechanisms of the DASH diet in improving FBG and lipid profile were explained by the fiber from whole grains, legumes, and nuts which reduce glucose absorption as well as improved insulin demand and $\beta$-cell function, whereas polyunsaturated fats from vegetable oils and nuts could reduce postprandial glucose, triglycerides, and increase skeletal muscle cell membrane fluidity and glucose uptake [31,32].

Beside the DM and healthy heart diet, the second reason for the improvement in some clinical outcomes in the elderly with poorly controlled type $2 \mathrm{DM}$ was due to them undertaking physical exercise regularly. In this study, the family member of the elderly person accompanied them to perform walking for at least 30 min per day, 3 - 5 days a week. Walking is a kind of exercise which improves oxygen consumption and increases the function of the cardiovascular and respiratory systems as well as improving physiological parameters such as fasting blood glucose and lipid profiles. Moreover, walking can restore the endothelial function and reduce arterial stiffness which is a positive denominator for developing cardiovascular complications in patients with type 2 DM [33].

The last reason for the improvement in some clinical outcomes in the elderly with poorly controlled type $2 \mathrm{DM}$ in the EG were that they took medications regularly. In this study, most of them received medication from the doctor such as metformin, amlodipine, and simvastatin. Also, the researchers provided a medication log book for the elderly in the EG. Thus, they could record their medications activity every day. Metformin reduces FBG by $50-70 \mathrm{mg} / \mathrm{dl}$ and it is linked with lower cardiovascular risk in the elderly with diabetes [34]. Amlodipine effectively reduces blood pressure and CVD risk [35]. 
http://wjst.wu.ac.th

While simvastatin is to prevent CVD complications by reducing risk factors of CVD complications such as hypercholesterolemia, LDL-cholesterol, and HDL-cholesterol [36].

However, according to the DBP pre-test (Table 4) there was a significant difference between the EG and CG. Also, the DBP post-test (Table 4) showed that there was no significant difference between the EG and CG after the program. These results occurred due to DBP in the EG and CG being at a normal level both before the program and after it.

\section{Conclusions}

In this study, a cardiovascular self-management support program consisting of assess, advise, agree, assist, and arrange was trailed. This program was specifically individualized and directed to improve the prevention of cardiovascular complications behaviors and clinical outcomes in the elderly with poorly controlled type $2 \mathrm{DM}$ to prevent CVD complications. The findings of this study showed that the cardiovascular self-management support program effectively improved the PCCB and some clinical outcomes which were FBG, total-cholesterol, HDL- cholesterol, LDL- cholesterol, and SBP in the experimental group than in the control group except DBP after 8 weeks. The results indicate that this program is beneficial, feasible, effective, and appropriate for elderly patients with poorly controlled type 2 DM.

\section{Acknowledgements}

This study was supported by a scholarship from the Graduate School, Prince of Songkla University, Thailand and Thailand's Education Hub for ASEAN Countries (TEH-AC).

\section{References}

[1] International Diabetes Federation. Diabetes Atlas 2015. $6^{\text {th }}$ eds. Philadelphia, 2015, p. 102.

[2] ME Otiniano, SA Snih, JS Goodwin, L Ray, M Alghatrif and KS Markides. Factors associated with poor glycemic control in older Mexican American diabetics aged 75 years and older. J. Diabet. Complicat. 2012; 26, 181-6.

[3] American Diabetes Association. Available at: http:/care.diabetesjournals.org/content/suppl/2014/ 12/23/38.Supplement_1.DC1/January_Supplement_Combined_Final.6-99.pdf, accessed July 2015.

[4] VD Tata. Age-related impairment of pancreatic beta-cell function: Pathophysiological and cellular mechanisms. Front. Endocrinol. 2014; 5, 138.

[5] JB Halter, N Musi, FMF Home, JP Crandall, A Goldberg, L Harkless and KP High. Diabetes and cardiovascular disease in older adults: Current status and future directions. Diabetes 2014; 63, 257889.

[6] MS Kirkman, VJ Briscoe, N Clark, H Florez, LB Haas, JB Halter and CS Swift. Diabetes in older adults. Diabet. Care 2012; 35, 2650-64.

[7] BJ Gates and KM Walker. Physiological changes in older adults and their effect on diabetes treatment. Diabet. Spectr. 2014; 27, 20-29.

[8] N Chiniwala and S Jabbour. Management of diabetes mellitus in the elderly. Curr. Opin. Endocrinol. Diabet. Obes. 2011; 18, 148-52.

[9] MDA Kalofoutis, C Kalofoutis, C Piperi, A Kalofoutis, F Harris and D Phoenix. Type II diabetes mellitus and cardiovascular risk factors: Current therapeutic approaches. Exp. Clin. Cardio. 2007; 12, 17-28.

[10] G Choi, SM Jang and HW Nam. Current status of self-management and barriers in elderly diabetic patient. Korean Diabet. J. 2008; 32, 280-9.

[11] K Sung. The effects of elderly diabetes mellitus patients' self-care behavior and health conservation on cardiovascular risk factors. J. Korean Acad. Comm. Health Nurs. 2015; 26, 150-9.

[12] TA Miller and MRD Matteo. Importance of family/social support and impact on adherence to diabetic therapy. Diabet. Metab. Syndr. Obes. 2013; 6, 421-6.

[13] AN Brewer-Lowry, TA Arcury, RA Bell and SA Quandt. Differentiating approaches to diabetes self-management of multi-ethnic rural older adults at the extremes of glycemic control. Gerontologist 2010; 50, 657-67.

[14] RE Glasgow, CL Davis, MM Funnell and A Beck. Implementing practical interventions to support chronic illness self-management. Joint Comm. J. Qual. Saf. 2003; 29, 563-74. 
http://wjst.wu.ac.th

[15] RE Glasgow, MM Funnell, AE Bonomi, C Davis, V Beckham and EH Wagner. Self-management aspects of the improving chronic illness care breakthrough series: Implementation with diabetes and heart failure teams. Ann. Behav. Med. 2002; 24, 80-7.

[16] N Suwankruhasn, L Pothiban, S Panuthai and P Boonchuang. Effects of a self-management support program for Thai people diagnosed with metabolic syndrome. Pacific Rim. Int. J. Nurs. Res. 2013; 17, 371-83.

[17] T Kurniwawan, W Sae-Sia, K Maneewat and W Petpichetchian. The effect of a self-management support program on the achievement of goals in diabetic foot care behaviors in Indonesian Diabetic Patients. Nurs. Med. J. Nurs. 2011; 1, 195-210.

[18] RA Pamungkas. 2015, The Effect of Dietary Behaviors among Muslim Patients with Poorly Controlled Type 2 Diabetes Mellitus in Community Setting in Indonesia. MNS. Thesis. Prince of Songkla University, Songkhla, Thailand.

[19] Pemkot Cilegon Resmikan Public Health Center, Available at: http://radar banten.co.id, accessed July 2015.

[20] Ahyana. 2013, The Effect of Self-Efficacy Enhancing Cardiac Rehabilitation Program on Health Behaviors among Patients with Myocardial Infarction in Aceh Indonesia. MNS. Thesis. Prince of Songkla University, Songkhla, Thailand.

[21] U Gunasekaran and M Gannon. Type 2 diabetes and the aging pancreatic beta cell. Aging 2011; 3, 565-75.

[22] EJ Nicklett and J Liang. Diabetes-related support, regimen adherence, and health decline among older adults. J. Gerontol. B Psychol. Sci. Soc. Sci. 2010; 65, 390-9.

[23] T Bodenheimer and MA Handley. Goal-setting for behavior change in primary care: An exploration and status report. Patient Educ. Couns. 2009; 76, 174-80.

[24] EA Beverly, S Fitzgerald, L Sitnikov, OP Ganda, AE Caballero and K Weinger. Do older adults aged 60-75 years benefit from diabetes behavioral interventions? Diabet. Care 2013; 36, 1501-6.

[25] L Melchior, B Carter, A Helsley, JK Ernest and D Friesner. The diabetes disease state management exemplar. Nurs. Econ. 2010; 28, 7.

[26] M Handley, K MacGregor, D Schillinger, C Sharifi, S Wong and T Bodenheimer. Using action plans to help primary care patients adopt healthy behaviors: A descriptive study. J. Am. Board Fam. Med. 2006; 19, 224-31.

[27] E Suhl and P Bonsignor. Diabetes self-management education for older adults: General principles and practical application. Diabet. Spectr. 2006; 19, 234-40.

[28] EG Eakin, SS Bull, KM Riley, MM Reeves, P McLaughlin and S Gutierrez. Resources for health: A primary-care-based diet and physical activity intervention targeting urban latinos with multiple chronic conditions. Health Psychol. 2007; 26, 392-400.

[29] L Fan and S Sidani. Effectiveness of diabetes self-management education intervention elements: A meta-analysis. Can. J. Diabet. 2009; 33, 18-26.

[30] L Azadbakht, NRP Fard, M Karimi, MH Baghaei, PJ Surkan, M Rahimi and WC Willett. Effects of the dietary approaches to stop hypertension (DASH) eating plan on cardiovascular risks among type 2 diabetic patients: A randomized crossover clinical trial. Diabet. Care 2011; 34, 55-7.

[31] AW Barclay, P Petocz, J McMillan-Price, VM Flood, T Prvan, P Mitchell and JC Brand-Miller. Glycemic index, glycemic load, and chronic disease risk: A meta-analysis of observational studies. Am. J. Clin. Nutr. 2008; 87, 627-37.

[32] K Murakami, H Okubo and S Sasaki. Effect of dietary factors on incidence of type 2 diabetes: A systematic review of cohort studies. J. Nutr. Sci. Vitaminol. 2005; 51, 292-310.

[33] ZC Thent, S Das and LJ Henry. Role of exercise in the management of diabetes mellitus: The global scenario. PloS One 2013; 8, e80436.

[34] A Solini, G Penno, E Bonora, C Fondelli, E Orsi, R Trevisan and G Pugliese. Age, renal dysfunction, cardiovascular disease, and antihyperglycemic treatment in type 2 diabetes mellitus: Findings from the renal insufficiency and cardiovascular events Italian multicenter study. J. Am. Geriatr. Soc. 2013; 61, 1253-61.

[35] M Devabhaktuni and S Bangalore. Fixed combination of amlodipine and atorvastatin in cardiovascular risk management: patient perspectives. Vasc. Health Risk Manag. 2009; 5, 377-87.

[36] WE Boden, JL Probstfield, T Anderson, BR Chaitman, P Desvignes-Nickens, K Koprowicz and W Weintraub. Niacin in patients with low HDL cholesterol levels receiving intensive statin therapy. New England J. Med. 2011; 365, 2255-67. 